\title{
Prevalence and Determinants of Diabetes and Prediabetes in Southwestern Iran: The Khuzestan Comprehensive Health Study (KCHS)
}

\section{Sanam Hariri}

Tehran University of Medical Sciences

\section{Zahra Rahimi}

Ahvaz Jundishapur University of Medical Sciences

Nahid Hashemi Madani

Iran University of Medical Sciences

\section{Seyyed Ali Mard}

Ahvaz Jundishapur University of Medical Sciences

\section{Farnaz Hashemi}

Tehran University of Medical Sciences

\section{Zahra Mohammadi}

Tehran University of Medical Sciences

\section{Leila Danehchin}

Behbahan University of Medical Sciences

\section{Farhad Abolnezhadian}

Shoushtar University of Medical Sciences

\section{Aliasghar Valipour}

Abadan Faculty of Medical Sciences

\section{Yousef Paridar}

Dezful University of Medical Sciences

Mohammad Mahdi Mir-Nasseri

Tehran University of Medical Sciences

Alireza Khajavi

Shahid Beheshti University of Medical Sciences

\section{Sahar Masoudi}

Tehran University of Medical Sciences

\section{Saba Alvand}

Tehran University of Medical Sciences

\section{Bahman Cheraghian}

Ahvaz Jundishapur University of Medical Sciences

Ali Akbar Shayesteh 
Ahvaz Jundishapur University of Medical Sciences

Mohammad E. Khamseh

Iran University of Medical Sciences

Hossein Poustchi ( $\boldsymbol{Q}$ h.poustchi@gmail.com )

Tehran University of Medical Sciences

\section{Research Article}

Keywords: Diabetes, Prediabetes, Epidemiology, Risk-factors, Low and middle-income countries, MiddleEast, Iran

Posted Date: January 15th, 2021

DOl: https://doi.org/10.21203/rs.3.rs-144637/v1

License: (c) (1) This work is licensed under a Creative Commons Attribution 4.0 International License. Read Full License 


\section{Abstract}

Background: The Middle East and North Africa (MENA) is postulated to have the highest increase in the prevalence of diabetes by 2030; however, studies on the epidemiology of diabetes are rather limited across the region, including in Iran.

Methods: This study was conducted between 2016 and 2018 among Iranian adults aged 20 to 65 years residing in Khuzestan province, southwestern Iran. Diabetes was defined as fasting blood sugar (FBS) $\geq$ $126 \mathrm{mg} / \mathrm{dl}$ and/or taking oral anti-diabetic medications. Prediabetes was defined as FBS $\geq 100$ but $\leq$ $125 \mathrm{mg} / \mathrm{dl}$. Multinomial logistic regression models were used to examine the association of multiple risk factors that attained significance on the outcome.

Results: Overall, 30,500 participants were recruited; the mean ( $\pm S D)$ age was $41.6( \pm 11.9)$ years. The prevalence of prediabetes and diabetes were $30.8 \%$ and $15.2 \%$, respectively. We found a comparable prevalence of diabetes in both sexes, although it was higher among illiterates, urban residents, married people, and smokers. Participants aged $\geq 50$ and those with Body Mass Index (BMI) $\geq 30 \mathrm{~kg} / \mathrm{m}^{2}$ were more likely to be affected by diabetes [RR: $18.5(16.4,21.0)$ and $3.2(2.9,3.5)]$. Hypertension [RR: 5.1 $(4.7,5.4)]$, waist circumference (WC) $\geq 90 \mathrm{~cm}$ [RR: 3.6 (3.3,3.9)], and family history [RR: $2.4(2.2,2.6)]$ were also significantly associated with diabetes. For prediabetes, the main risk factors were age $\geq 50$ [RR: 2.4 $(2.3,2.6)], \mathrm{BMI} \geq 30 \mathrm{~kg} / \mathrm{m}^{2}$ [RR: $\left.1.9(1.7,2.0)\right]$, hypertension and $\mathrm{WC} \geq 90 \mathrm{~cm}[\mathrm{RR}: 1.7(1.6,1.8)]$.

Conclusions: Prediabetes and diabetes are prevalent in southwestern Iran. The major determinants are older age, obesity, and the presence of hypertension. Further interventions are required to escalate diabetes prevention and diagnosis in high-risk areas across Iran.

\section{Background}

The Middle East and North Africa (MENA) region holds the highest prevalence of diabetes mellitus (DM) worldwide, and is estimated to have the most significant increase in this prevalence in the coming years (1). However, there are limited population-based studies on the epidemiology and determinants of diabetes in MENA countries, including Iran (2).

By 2035, the number of adults with diabetes will increase by $55 \%$ globally, and the greatest proportional increase is expected in low-income countries, followed by low to middle-income (108 and 60\%) (3). The MENA region has the highest worldwide prevalence of diabetes $(10.9 \%)$ and is estimated to have the second-highest global increase (96.2\%) in the number of people with diabetes by 2035 (3). Moreover, nearly half of all diabetes deaths in this region occur among people under 60 years old. These premature deaths may be due to the new emerging risk factors, delayed diagnoses, and weak health-care systems that are not competent to bear the growing burden (4). Aging populations, together with rapid urbanization that has brought major behavioral and lifestyle changes, have resulted in a dramatic increase in the prevalence of diabetes in such regions (5). Identifying the main traditional and non- 
traditional risk factors is crucial for developing preventive strategies and early diagnosis of diabetes in low-income countries (2).

By 2035 , the number of people with diabetes has been projected to increase by $91 \%$ in Iran, and the economic burden of diabetes will increase markedly in the coming decades $(6,7)$. Despite the availability of medications and insulin coverage in Iran, control of diabetes remains suboptimal (8). In line with global initiatives to reduce the diabetes burden, Iran has made great prevention efforts in recent decades $(9-11)$. However, the current role of diabetes risk factors remains poorly identified among patients in different areas across Iran $(2,8)$. The present study aimed to investigate the prevalence and determinants of prediabetes and diabetes in a large population from southwestern Iran.

\section{Methods}

\section{Study design}

The Khuzestan comprehensive health study (KCHS) was conducted as a large cross-sectional study between October 2016 and November 2018 to assess the health conditions of 30,500 Iranian adults. The study site was Khuzestan province, located in southwestern Iran. This province covers more than $63,000 \mathrm{~km}^{2}$ and is home to a diverse population of nearly five million, including Fars, Arab, Bakhtiari, Kurd, and Lur ethnic groups. The study population includes people aged 20 to 65 years, residing in urban and rural areas of 27 counties in the province. Written informed consent was obtained from all participants. All procedures performed in the study were in accordance with the ethical guidelines of the Declaration of Helsinki and the ethics committee of the National Institute for Medical Research Development (NIMAD) has approved the study protocol. The KCHS methodology has been detailed elsewhere (12).

\section{Study procedures}

A multistage random sampling method was used to select participants. Trained staff went door to door to explain the study and invite the participants to the pre-defined study sites on the next day. All participants provided informed consent upon registration. Fifteen $\mathrm{mL}$ of blood were obtained from each individual, divided into one clot tube and one EDTA tube. Blood samples were centrifuged at $3000 \mathrm{rpm}$ for 10 min to separate serum; thereafter, serum level of fasting blood sugar (FBS) was measured by BT 1500 AutoAnalyzer, using commercial kits (Pars Azmoon, Iran). To reduce the measurement error, anthropometric data were gathered after blood sample collection, in a fasting state for 8 to 12 hours. Height and weight were measured by the Seca 206 body meter measuring tape with Wall Stop and the Seca 762 mechanical flat scale, respectively, and the Seca 203 circumference measuring tape was used to measure waist circumference (WC). Blood pressure was measured using aneroid sphygmomanometers (Riester, Germany), twice from each arm in the sitting position. All measurements were in accordance with the US National Institutes of Health protocols. Data on demographics, socioeconomic status, and lifestyle habits were collected afterward by staff-administered questionnaires. 


\section{Definition of variables and study outcomes}

Diabetes was defined as FBS $\geq 126 \mathrm{mg} / \mathrm{dl}$ and/or taking anti-diabetic medications. Prediabetes was defined as FBS $\geq 100$ but $\leq 125 \mathrm{mg} / \mathrm{dl}$. General obesity was determined based on Body mass index (BMI), which is calculated by dividing weight $(\mathrm{kg})$ by the square of the height $(\mathrm{m})$ and categorized according to the World Health Organization (WHO) cut-off points (13). BMl scores less than $25 \mathrm{~kg} / \mathrm{m}^{2}$, between 25 and $29.9 \mathrm{~kg} / \mathrm{m}^{2}$, and $\geq 30 \mathrm{~kg} / \mathrm{m}^{2}$ were defined as normal weight, overweight, and obese, respectively. Abdominal obesity was characterized by a $\mathrm{WC} \geq 90 \mathrm{~cm}$ for both men and women. Following major guidelines, hypertension (HTN) was defined as systolic blood pressure (SBP) $\geq 140 \mathrm{mmHg}$ and/or diastolic blood pressure (DBP) $\geq 90 \mathrm{mmHg}$ and/or taking antihypertensive medications (14). Wealth score index was calculated using multiple correspondence analysis (MCA) with the following variables: house area, freezer, washing machine, dishwasher, laptop, internet, car type, TV type, indoor bathroom, vacuum cleaner, mobile use, and foreign travels.

\section{Statistical analysis}

Data are described by the mean and standard deviation (SD) or frequency and percentage, where appropriate. A multinomial logistic regression model was used to assess the impact of the covariates on the risk of prediabetes or diabetes, which led to relative risks (RR) as the measure of association. In this model, individuals with prediabetes and diabetes were compared with normal participants. Each of the covariates sex, age, BMI, WC, HTN, diabetes family, and education have been put in the model, once alone and once adjusted for smoking, marital status, residence, and wealth index. These four variables were selected as the adjustments since the preliminary assessments showed that the prevalence of prediabetes and diabetes did not differentiate between these variables' strata. The analyses were performed using the statistical software Stata (version 12), and the chosen significance level was 0.05 .

\section{Results}

Overall, 30,500 individuals were included in the analysis, of whom 19,600 (64.3\%) were women. The mean age of participants was $41.6 \pm 11.9$ years. The mean BMI and WC were $27.6 \pm 5.3 \mathrm{~kg} / \mathrm{m}^{2}$ and 92.5 $\pm 13.4 \mathrm{~cm}$, respectively. Overall, the majority were married (83.0\%), urban residents $(73.1 \%)$, had primary education (44.2\%), and were never-smokers (89.1\%). HTN and family history of diabetes were observed in $19.7 \%$ and $34.2 \%$, respectively (Table 1 ).

Among all participants, 9,405 (30.8\%) were identified to have prediabetes, and 4,646 (15.2\%) had diabetes. Self-reported diabetes was among 2,694 (8.9\%) individuals. The highest prevalence of diabetes and prediabetes was observed among people aged $\geq 50$ years $(32.2 \%$ and $33.0 \%)$ and those with $\mathrm{BMI} \geq$ $30 \mathrm{~kg} / \mathrm{m}^{2}(20.9 \%$ and $34.7 \%)$. Prevalence of diabetes was comparable in both sexes (15\%), while it was higher among urban residents and marrieds (16.4\% and $16.1 \%)$, the illiterates (24.6\%), and those who had WC $\geq 90 \mathrm{~cm}(20.5 \%)$, and HTN (33.4\%). Regarding prediabetes, the prevalence was slightly higher among men $(32.0 \%)$ and urban residents (31.5\%), and those who had WC $\geq 90 \mathrm{~cm}(33.2 \%)$ (Table 1). 
Table 1. Characteristics of the Khuzestan Comprehensive Health Study (KCHS) participants. 


\begin{tabular}{|c|c|c|c|c|}
\hline Variable & & Total number (\%) & Prediabetes & Diabetes \\
\hline Total & & 30500 & 9405 & 4646 \\
\hline \multirow[t]{2}{*}{ Sex } & Male & $10898(35.7 \%)$ & $\begin{array}{l}3486(32.0 \\
\%)\end{array}$ & $\begin{array}{l}1655(15.2 \\
\%)\end{array}$ \\
\hline & Female & $19600(64.3 \%)$ & $\begin{array}{l}5919(30.2 \\
\%)\end{array}$ & $\begin{array}{l}2991(15.3 \\
\%)\end{array}$ \\
\hline \multicolumn{5}{|l|}{ Age (years) } \\
\hline & $20-35$ & $10273(33.7 \%)$ & $\begin{array}{l}2767(26.9 \\
\%)\end{array}$ & $347 \quad(3.4 \%)$ \\
\hline & $35-49.9$ & $11676(38.4 \%)$ & $\begin{array}{l}3815(32.7 \\
\%)\end{array}$ & $\begin{array}{l}1557(13.3 \\
\%)\end{array}$ \\
\hline & $\geq 50$ & $8492(27.9 \%)$ & $\begin{array}{l}2802(33.0 \\
\%)\end{array}$ & $\begin{array}{l}2735(32.2 \\
\%)\end{array}$ \\
\hline \multicolumn{5}{|l|}{$\mathrm{BMI}\left(\mathrm{Kg} / \mathrm{m}^{2}\right)$} \\
\hline & $<25$ & $9829(32.4 \%)$ & $\begin{array}{l}2596(26.4 \\
\%)\end{array}$ & $887(9.0 \%)$ \\
\hline & $25-29.9$ & $11440(37.7 \%)$ & $\begin{array}{l}3620(31.6 \\
\%)\end{array}$ & $\begin{array}{l}1824(15.9 \\
\%)\end{array}$ \\
\hline & $\geq 30$ & $9088(29.9 \%)$ & $\begin{array}{l}3152(34.7 \\
\%)\end{array}$ & $\begin{array}{l}1903(20.9 \\
\%)\end{array}$ \\
\hline \multicolumn{5}{|l|}{$\begin{array}{l}\text { Waist circumference } \\
\text { (cm) }\end{array}$} \\
\hline & $<90$ & $12405(40.9 \%)$ & $\begin{array}{l}3407(27.5 \\
\%)\end{array}$ & $941 \quad(7.6 \%)$ \\
\hline & $\geq 90$ & $17953(59.1 \%)$ & $\begin{array}{l}5962(33.2 \\
\%)\end{array}$ & $\begin{array}{l}3673(20.5 \\
\%)\end{array}$ \\
\hline \multirow[t]{2}{*}{ Hypertension } & No & $24493(80.3 \%)$ & $\begin{array}{l}7507 \text { (30.7 } \\
\%)\end{array}$ & $\begin{array}{l}2641(10.8 \\
\%)\end{array}$ \\
\hline & Yes & $5993(19.7 \%)$ & $\begin{array}{l}1895(31.6 \\
\%)\end{array}$ & $\begin{array}{l}2004(33.4 \\
\%)\end{array}$ \\
\hline \multirow[t]{2}{*}{ Diabetes family history } & No & $20025(65.8 \%)$ & $\begin{array}{l}6186(30.9 \\
\%)\end{array}$ & $\begin{array}{l}2299(11.5 \\
\%)\end{array}$ \\
\hline & Yes & $10418(34.2 \%)$ & $\begin{array}{l}3205(30.8 \\
\%)\end{array}$ & $\begin{array}{l}2338(22.4 \\
\%)\end{array}$ \\
\hline \multicolumn{5}{|l|}{ Education } \\
\hline & Illiterate & $6606(21.7 \%)$ & $\begin{array}{l}1983(30.0 \\
\%)\end{array}$ & $\begin{array}{l}1626(24.6 \\
\%)\end{array}$ \\
\hline
\end{tabular}




\begin{tabular}{|c|c|c|c|c|}
\hline & Elementary & $13480(44.2 \%)$ & $\begin{array}{l}4305(31.9 \\
\%)\end{array}$ & $\begin{array}{l}2072(15.4 \\
\%)\end{array}$ \\
\hline & Secondary & 7844 (25.7 \%) & $\begin{array}{l}2342(29.9 \\
\%)\end{array}$ & $802(10.2 \%)$ \\
\hline & $\begin{array}{l}\text { Higher } \\
\text { education }\end{array}$ & $2563 \quad(8.4 \%)$ & 773 (30.2 \%) & $145(5.7 \%)$ \\
\hline \multicolumn{5}{|c|}{ Cigarette smoking } \\
\hline & Never & $\begin{array}{l}27046(89.1 \\
\%)\end{array}$ & $\begin{array}{l}8410(31.1 \\
\%)\end{array}$ & $\begin{array}{l}4061(15.0 \\
\%)\end{array}$ \\
\hline & Past & 974 (3.2\%) & 301 (30.9 \%) & $251(25.8 \%)$ \\
\hline & Current & 2324 (7.7\%) & 649 (27.9 \%) & 311 (13.4 \%) \\
\hline \multirow[t]{2}{*}{ Marital status } & Single & $5178(17.0 \%)$ & $\begin{array}{l}1561(30.2 \\
\%)\end{array}$ & $566(10.9 \%)$ \\
\hline & Married & $25320(83.0 \%)$ & $\begin{array}{l}7844(31.0 \\
\%)\end{array}$ & $\begin{array}{l}4080(16.1 \\
\%)\end{array}$ \\
\hline \multirow[t]{2}{*}{ Residence } & Urban & $22284(73.1 \%)$ & $\begin{array}{l}7008 \text { (31.5 } \\
\%)\end{array}$ & $\begin{array}{l}3656 \text { (16.4 } \\
\%)\end{array}$ \\
\hline & Rural & $8213(26.9 \%)$ & $\begin{array}{l}2397(29.2 \\
\%)\end{array}$ & $990(12.1 \%)$ \\
\hline \multicolumn{5}{|l|}{ Wealth index } \\
\hline & $\mathrm{Q}_{1}$ & $25 \%$ & $\begin{array}{l}2273(29.8 \\
\%)\end{array}$ & $\begin{array}{l}1126(14.7 \\
\%)\end{array}$ \\
\hline & $\mathrm{Q}_{2}$ & $25 \%$ & $\begin{array}{l}2345(31.2 \\
\%)\end{array}$ & $\begin{array}{l}1151(15.3 \\
\%)\end{array}$ \\
\hline & $\mathrm{Q}_{3}$ & $25 \%$ & $\begin{array}{l}2459(30.4 \\
\%)\end{array}$ & $\begin{array}{l}1190(14.7 \\
\%)\end{array}$ \\
\hline & $\mathrm{Q}_{4}$ & $25 \%$ & $\begin{array}{l}2275(32.2 \\
\%)\end{array}$ & $\begin{array}{l}1147(16.2 \\
\%)\end{array}$ \\
\hline
\end{tabular}

Results on multivariate analysis of the factors associated with diabetes and prediabetes risk are demonstrated in Table 2. Compared to the participants aged under 35 years, those aged between 35-49.9 years [RR $(95 \% \mathrm{Cl}) ; 5.02(4.43,5.69)]$ or $\geq 50$ years [RR $(95 \% \mathrm{Cl}) ; 18.54(16.39,20.98)]$ were more likely to be affected by diabetes. Moreover, compared to the participants with $\mathrm{BMI}<25 \mathrm{~kg} / \mathrm{m}^{2}$, those who had BMI $25-29.9 \mathrm{~kg} / \mathrm{m}^{2}[\mathrm{RR}(95 \% \mathrm{Cl}) ; 2.06(1.88,2.25)]$ or $\mathrm{BMI} \geq 30 \mathrm{~kg} / \mathrm{m}^{2}[\mathrm{RR}(95 \% \mathrm{Cl}) ; 3.17(2.89,3.47)]$ were more likely to be affected by diabetes. HTN [RR (95\% Cl); $5.1(4.7,5.4)], W C \geq 90 \mathrm{~cm}[\mathrm{RR}(95 \% \mathrm{Cl}) ; 3.6(3.3$, $3.9)]$, and history of diabetes in first-degree family member [RR $(95 \% \mathrm{Cl}) ; 2.4(2.2,2.6)]$ were also found to 
be significantly associated with diabetes. Furthermore, higher education was associated with the lowest risk of diabetes [RR $(95 \% \mathrm{Cl}) ; 0.10(0.08,0.12)]$ (Table 2$)$.

Regarding the factors associated with prediabetes, results showed that compared to the participants aged under 35 years, those aged between $35-49.9$ [RR $(95 \% \mathrm{Cl}) ; 1.57(1.48,1.67)]$ or $\geq 50$ years [RR $(95 \%$ $\mathrm{Cl}) ; 2.44(2.27,2.61)]$ were more likely to be affected by prediabetes. Similarly, compared to the participants with BMI $<25 \mathrm{~kg} / \mathrm{m}^{2}$, those who had BMI 25-29.9 kg/m² $[\mathrm{RR}(95 \% \mathrm{Cl}) ; 1.44(1.36,1.54)]$ or $\mathrm{BMI} \geq 30 \mathrm{~kg} / \mathrm{m}^{2}$ [RR $\left.(95 \% \mathrm{Cl}) ; 1.86(1.74,1.99)\right]$ were more likely to be affected by prediabetes. HTN [RR $(95 \% \mathrm{Cl}) ; 1.71(1.60,1.83)], \mathrm{WC} \geq 90 \mathrm{~cm}[\mathrm{RR}(95 \% \mathrm{Cl}) ; 1.67(1.59,1.77)]$, and having a first-degree relative with diabetes [RR $(95 \% \mathrm{Cl}) ; 1.22(1.15,1.29)]$ were significantly associated with prediabetes. Similar to diabetes, the highest educational degree was also associated with the lowest risk of prediabetes [RR (95\% $\mathrm{Cl}) ; 0.58(0.51,0.64)]$. Furthermore, female sex was slightly protective against prediabetes [(RR $(95 \% \mathrm{Cl})$; $0.88(0.83,0.93)]$ (Table 2$)$.

Table 2. Univariate and multivariate analysis of risk factors associated with diabetes and prediabetes in the Khuzestan study. 


\begin{tabular}{|c|c|c|c|c|c|}
\hline & & Prediabetes & & Diabetes & \\
\hline Variables & & $\begin{array}{l}\text { Unadjusted. } \\
\text { RR }\end{array}$ & $\begin{array}{l}\text { Adjusted. } \\
\mathrm{RR}^{\star}\end{array}$ & & \\
\hline & & & (95\% Cl) & & \\
\hline Sex & Male & & & & \\
\hline & Female & $\begin{array}{l}0.91(0.87 \\
0.96)\end{array}$ & $\begin{array}{l}0.88(0.83, \\
0.93)\end{array}$ & $\begin{array}{l}0.97(0.91, \\
1.04)\end{array}$ & $\begin{array}{l}1.01(0.94, \\
1.09)\end{array}$ \\
\hline Age (years) & $<35$ & & & & \\
\hline & $35-49.9$ & $\begin{array}{l}1.57(1.48 \\
1.66)\end{array}$ & $\begin{array}{l}1.57(1.48, \\
1.67)\end{array}$ & $\begin{array}{l}5.1(4.51, \\
5.75)\end{array}$ & $\begin{array}{l}5.02(4.43, \\
5.69)\end{array}$ \\
\hline & $\geq 50$ & $\begin{array}{l}2.45(2.29 \\
2.63)\end{array}$ & $\begin{array}{l}2.44(2.27 \\
2.61)\end{array}$ & $\begin{array}{l}19.1(16.94, \\
21.52)\end{array}$ & $\begin{array}{l}18.54(16.39 \\
20.98)\end{array}$ \\
\hline $\operatorname{BMI}\left(\mathrm{Kg} / \mathrm{m}^{2}\right)$ & $<25$ & & & & \\
\hline & $25-29.9$ & $\begin{array}{l}1.48(1.39 \\
1.57)\end{array}$ & $\begin{array}{l}1.44(1.36 \\
1.54)\end{array}$ & $\begin{array}{l}2.18(1.99 \\
2.38)\end{array}$ & $\begin{array}{l}2.06(1.88, \\
2.25)\end{array}$ \\
\hline & $\geq 30$ & $\begin{array}{l}1.91(1.79 \\
2.04)\end{array}$ & $\begin{array}{l}1.86(1.74, \\
1.99)\end{array}$ & $\begin{array}{l}3.38 \text { (3.09, } \\
3.69)\end{array}$ & $\begin{array}{l}3.17(2.89 \\
3.47)\end{array}$ \\
\hline Waist & $<90$ & & & & \\
\hline & $\geq 90$ & $\begin{array}{l}1.70(1.61, \\
1.79)\end{array}$ & $\begin{array}{l}1.67(1.59 \\
1.77)\end{array}$ & $\begin{array}{l}3.78 \text { (3.50, } \\
4.09)\end{array}$ & $\begin{array}{l}3.61 \text { (3.33, } \\
3.91)\end{array}$ \\
\hline Hypertension & No & & & & \\
\hline & Yes & $\begin{array}{l}1.73(1.62, \\
1.85)\end{array}$ & $\begin{array}{l}1.71(1.60, \\
1.83)\end{array}$ & $\begin{array}{l}5.20(4.83 \\
5.6)\end{array}$ & $\begin{array}{l}5.05(4.68, \\
5.44)\end{array}$ \\
\hline Diabetes family & No & & & & \\
\hline & Yes & $\begin{array}{l}1.23(1.16 \\
1.29)\end{array}$ & $\begin{array}{l}1.22(1.15 \\
1.29)\end{array}$ & $\begin{array}{l}2.41(2.25 \\
2.57)\end{array}$ & $\begin{array}{l}2.38(2.22, \\
2.55)\end{array}$ \\
\hline Education & Illiterate & & & & \\
\hline & Elementary & $\begin{array}{l}0.92(0.86 \\
0.98)\end{array}$ & $\begin{array}{l}0.85(0.79 \\
0.91)\end{array}$ & $\begin{array}{l}0.54(0.50 \\
0.58)\end{array}$ & $\begin{array}{l}0.43(0.40 \\
0.47)\end{array}$ \\
\hline & Secondary & $\begin{array}{l}0.75(0.70 \\
0.81)\end{array}$ & $\begin{array}{l}0.65(0.59 \\
0.70)\end{array}$ & $\begin{array}{l}0.31(0.29 \\
0.35)\end{array}$ & $\begin{array}{l}0.21(0.19 \\
0.23)\end{array}$ \\
\hline & $\begin{array}{l}\text { Higher } \\
\text { education }\end{array}$ & $\begin{array}{l}0.71 \\
0.79)\end{array}$ & $\begin{array}{l}0.58 \\
0.64)\end{array}$ & $\begin{array}{l}0.16(0.14, \\
0.19)\end{array}$ & $\begin{array}{l}0.10(0.08 \\
0.12)\end{array}$ \\
\hline
\end{tabular}


*Data are adjusted for smoking (never vs. ever), marital status (single vs. married), residence (urban vs. rural), and wealth index.

*RR: Relative risk

We further evaluated the characteristics of the normal weight and underweight participants affected by diabetes (Table 3). Overall, 887 participants ( $50.2 \%$ female) with $\mathrm{BMl}<25 \mathrm{~kg} / \mathrm{m}^{2}$ were identified to have diabetes. The mean WC in this group was $86.1 \pm 8.8 \mathrm{~cm}$, and the majority had a WC $<90 \mathrm{~cm}(63 \%)$. The mean age of these participants was $50.5 \pm 10.7$ years, and the majority aged $\geq 50$ years $(61.4 \%)$, were married (85.7\%) and were urban residents (71.8\%). Most of these individuals had no history of HTN (64\%) and smoking (82.1\%), while nearly half had a family history of diabetes (48.2\%). (Table 3 ).

Table 3. Characteristics of the Khuzestan study participants with diabetes who had Body Mass Index $(\mathrm{BMI})<25 \mathrm{~kg} / \mathrm{m} 2$ 


\begin{tabular}{|c|c|c|}
\hline Variable & & Number (\%) \\
\hline \multirow[t]{2}{*}{ Sex } & Male & $442(49.8 \%)$ \\
\hline & Female & $445(50.2 \%)$ \\
\hline \multicolumn{3}{|l|}{ Age (years) } \\
\hline & $<35$ & $96(10.8 \%)$ \\
\hline & $35-49.9$ & $246(27.8 \%)$ \\
\hline & $\geq 50$ & $544(61.4 \%)$ \\
\hline \multicolumn{3}{|c|}{ Waist circumference (cm) } \\
\hline & $<90$ & $557(62.8 \%)$ \\
\hline & $\geq 90$ & $330(37.2 \%)$ \\
\hline \multicolumn{3}{|l|}{ Hypertension } \\
\hline & No & $568(64.0 \%)$ \\
\hline & Yes & $319(36.0 \%)$ \\
\hline \multicolumn{3}{|l|}{ Diabetes } \\
\hline \multirow[t]{2}{*}{ family history } & No & $459(51.8 \%)$ \\
\hline & Yes & $427(48.2 \%)$ \\
\hline \multicolumn{3}{|l|}{ Education } \\
\hline & Illiterate & $309(34.9 \%)$ \\
\hline & Elementary & $393(44.4 \%)$ \\
\hline & Secondary & $160(18.1 \%)$ \\
\hline & Higher education & $24 \quad(2.7 \%)$ \\
\hline \multicolumn{3}{|l|}{ Smoking } \\
\hline & Never & $725(82.1 \%)$ \\
\hline & Ever & $158(17.9 \%)$ \\
\hline \multicolumn{3}{|l|}{ Marital Status } \\
\hline & Single & $127(14.3 \%)$ \\
\hline & Married & 760 (85.7\%) \\
\hline \multicolumn{3}{|l|}{ Residence } \\
\hline & Urban & 637 (71.8 \%) \\
\hline
\end{tabular}




\section{Discussion}

This study investigates the prevalence and determinants of prediabetes and diabetes in a populationbased sample of Iranian adults residing in southwestern Iran. Prediabetes with $30.8 \%$ and diabetes with $15.2 \%$ were more prevalent in this area than in most other parts of the country. In line with previous studies, older adults had the most significant relative risk for diabetes, followed by those with hypertension and abdominal obesity (15). For prediabetes, older age, general obesity, and hypertension were the most significant risk factors, similar to a previous study from southern Iran (16). Also, socioeconomic status was inversely associated with both diabetes and prediabetes prevalence. These findings indicate that urgent control measures are needed to impede the high burden of diabetes in this region.

Prevalence of diabetes in the present study was identical to a survey conducted by Yazdanpanah et al. in 2015 , which is the only available report on diabetes from southwestern Iran (15.2\% vs. $15.1 \%)(17)$ and comparable to two recent studies from central (16.1\%) (18) and Northern Iran (17.2\%) (7). However, this prevalence was nearly two-fold higher compared to the national estimations (19) and other parts of the country, including western (20), southeastern (21), and southern areas (22). Besides, the prevalence of self-reported diabetes was comparable to the national estimations (8.9 vs. 10\%) (23). For prediabetes, two population-based studies in central and southeastern Iran have reported a lower prevalence $(26 \%$ and $19 \%)$; however, individuals under 35 years were recruited in both studies (18). These comparisons indicate that diabetes is exceptionally prevalent in the southwestern region, and urgent interventions should be taken to scale-up preventive and diagnostic programs (10). Moreover, given the suboptimal national control of hyperglycemia in Iran, therapeutic interventions should be particularly expanded into high-risk populations (8).

Globally, elderly people are at substantial risk for diabetes (24). In this study, one-third of individuals above 50 years old had diabetes, which is similar to the results of an elderly-based survey conducted among people older than 60 years in southern Iran; however, their reported prevalence for prediabetes was two-fold higher than our estimation for elderlies (67\% vs. $33 \%$ ) (25). Although older age was also the most significant risk factor for prediabetes, the relative risk was much lower than diabetes (2.4 vs. 18.5). The second considerable diabetes risk factor was hypertension, having a 5 -fold higher relative risk in people with hypertension than those without such condition. According to a cohort of 4.1 million adults from the U.K, individuals with elevated blood pressure are at increased risk of diabetes, while the strength of this association declines with increasing age and BMI (26). Regarding obesity, some previous reports have emphasized the benefits of WC compared to BMI in predicting diabetes in the Iranian population. Similarly, WC showed a stronger association than BMI in the present study $(3.6 \mathrm{vs.} 3.2)(1,27)$, although for prediabetes this association was slightly stronger for BMI (1.9 vs. 1.7). 
A study from Northern Iran showed that having one or more than one family member with diabetes increases the odds of this disease to 2.3 and 4.2, respectively (7). Another cohort from the center of Iran showed that people with a first-degree family history were 3.3 times more likely to have the disease (28). Similarly, family history in first-degree relatives was among the most significant risk factors in our study, with a relative risk equal to 2.4. Also, among those with diabetes and normal BMI, approximately half had a family history of diabetes, and the majority were old. In a study conducted on over 9,000 adults, Mirzaei et al. have found a negative interaction between family history of diabetes and other risk factors only for BMI (29). Their results suggested that despite considering family history as an independent risk factor, as long as it is used as a tool to raise awareness and promote lifestyle changes, it would reduce the risk of developing diabetes in people with other risk factors such as obesity.

Evidence on the modifying effect of sex in the development of diabetes is controversial. Several Iranian studies have reported a higher prevalence among females $(1,30,31)$, and some others have not found any significant associations for sex (32). Similar to the study of Yazdanpanah et al. from southwestern Iran, we observed a comparable prevalence of diabetes in both sexes. Moreover, the female sex was slightly protective against prediabetes in our study. According to Khosravi et al., obesity is the most significant risk factor for sex inequalities in type 2 diabetes in Iranians; this can partly explain the observed difference in the prevalence of diabetes between sexes (33).

Many studies have confirmed the role of socioeconomic factors in developing diabetes (34). We observed higher diabetes prevalence among urban residents and illiterates, and higher education was protective against diabetes and prediabetes. These findings were in line with other studies on socioeconomic inequalities and diabetes in Iran $(18,35)$. Also, the prevalence of both conditions was higher among married individuals, consistent with the findings of Yazdanpanah et al. (17). Prevalence of diabetes in current smokers was similar to a study from Northern Iran (13.4\% vs. 12.1\%) (7). Both diabetes and prediabetes were more prevalent in ex and non-smokers. Although studies indicate that smoking increases the risk of diabetes, some evidence supports the reverse association (36). Our observed pattern for smoking was similar to a large Chinese study that has reported a significantly higher FBS in exsmokers, compared to the two other groups (37). Therefore, the association between smoking and diabetes in the Iranian population needs further investigation.

\section{Conclusions}

Prediabetes and diabetes are prevalent in southwestern Iran, and their prevalence is higher than in most parts of the country. The major determinants are older age, general and abdominal obesity, and the presence of hypertension. Further studies are needed to better understand the epidemiology of diabetes across Iran, and urgent interventions should be applied to escalate diabetes prevention, diagnosis, and treatment among high-risk populations residing in Iran.

\section{Abbreviations}


BMl: Body mass index

DBP: Diastolic blood pressure

DM: Diabetes mellitus

FBS: Fasting blood sugar

HTN: Hypertension

KCHS: Khuzestan Comprehensive Health Study

MCA: Multiple correspondence analysis

MENA: Middle East and North Africa

NIMAD: National Institute for Medical Research Development

RR: Relative risk

SBP: Systolic blood pressure

SD: Standard deviation

WC: Waist circumference

WHO: World Health Organization

\section{Declarations}

\section{Ethics approval and consent to participate:}

The ethics committee of the National Institute for Medical Research Development (NIMAD) has approved the study protocol (IR.NIMAD.REC.1394.002). Written informed consent was obtained from all participants.

Consent for publication:

Not Applicable

\section{Availability of data and materials}

The datasets used and/or analysed during the current study are available from the corresponding author on reasonable request.

Competing interests: 
The authors declare that they have no competing interests.

\section{Funding:}

This study was funded by the National Institute for Medical Research Development (NIMAD) [grant number 940406].

\section{Authors' contributions:}

S.H. drafted the manuscript. Z.R. and ME.KH. contributed to interpretation of the analyses and drafting of the manuscript. Z.M supervised the project and was responsible for quality control. N.HM. thoroughly revised the manuscript before submission. A.KH. and S.M. performed the analysis. S.A. contributed to the literature review. SA.M., F.A., L.D., A.V., F.H., MM.MN., B.CH., and Y.P. contributed to data collection. H.P. and AA.SH. contributed to designing, supervising, and coordinating the project. All authors read and approved the final manuscript.

\section{Acknowledgements:}

This large population-based study was executed by the cooperation of Digestive Diseases Research Institute (DDRI), the Iranian Blood Transfusion Organization (IBTO), Jundishapur and Dezful Universities of Medical Sciences, together with Abadan and Behbahan Faculties of Medicine.

\section{References}

1. Harati H, Hadaegh F, Saadat N, Azizi F. Population-based incidence of Type 2 diabetes and its associated risk factors: results from a six-year cohort study in Iran. BMC Public Health. 2009;9(1):186.

2. Shaghaghi A, Ahmadi A. Evidence Gap on the Prevalence of Non-conventional Risk Factors for Type 2 Diabetes in Iran. Osong public health and research perspectives. 2014;5(5):292-7.

3. Guariguata L, Whiting DR, Hambleton I, Beagley J, Linnenkamp U, Shaw JE. Global estimates of diabetes prevalence for 2013 and projections for 2035. Diabetes research and clinical practice. 2014;103(2):137-49.

4. Federation ID. IDF Diabetes Atlas 6th Edition. 2013.

5. Collaboration NCDRF. Worldwide trends in diabetes since 1980: a pooled analysis of 751 populationbased studies with 4.4 million participants. Lancet (London, England). 2016;387(10027):1513-30.

6. Javanbakht M, Mashayekhi A, Baradaran HR, Haghdoost A, Afshin A. Projection of Diabetes Population Size and Associated Economic Burden through 2030 in Iran: Evidence from MicroSimulation Markov Model and Bayesian Meta-Analysis. PloS one. 2015;10(7):e0132505-e.

7. Moosazadeh M, Afshari M, Jafari K, Kheradmand M, Kashi Z, Aarabi M, et al. Enrolment Phase Results of the Tabari Cohort Study: Comparing Family History, Lipids and Anthropometric Profiles Among Diabetic Patients. Osong public health and research perspectives. 2019;10(5):289-94. 
8. Esteghamati A, Larijani B, Aghajani MH, Ghaemi F, Kermanchi J, Shahrami A, et al. Diabetes in Iran: Prospective Analysis from First Nationwide Diabetes Report of National Program for Prevention and Control of Diabetes (NPPCD-2016). Sci Rep. 2017;7(1):13461-.

9. Farzadfar F, Murray CJ, Gakidou E, Bossert T, Namdaritabar H, Alikhani S, et al. Effectiveness of diabetes and hypertension management by rural primary health-care workers (Behvarz workers) in Iran: a nationally representative observational study. Lancet (London, England). 2012;379(9810):4754.

10. Noshad S, Afarideh M, Heidari B, Mechanick JI, Esteghamati A. Diabetes Care in Iran: Where We Stand and Where We Are Headed. Annals of global health. 2015;81(6):839-50.

11. Faraji O, Etemad K, Akbari Sari A, Ravaghi H. Policies and Programs for Prevention and Control of Diabetes in Iran: A Document Analysis. Glob J Health Sci. 2015;7(6):187-97.

12. Cheraghian B, Sharafkhah M, Mohammadi Z, Hariri S, Rahimi Z, Danehchin L, et al. The Khuzestan Comprehensive Health Study (KCHS): Methodology and Profile of Participants. Archives of Iranian medicine. 2020;23(10):653-7.

13. Appropriate body-mass index for Asian populations and its implications for policy and intervention strategies. Lancet (London, England). 2004;363(9403):157-63.

14. Armstrong C. High Blood Pressure: ACC/AHA Releases Updated Guideline. American family physician. 2018;97(6):413-5.

15. Ebrahimi H, Emamian MH, Hashemi H, Fotouhi A. High Incidence of Diabetes Mellitus Among a Middle-Aged Population in Iran: A Longitudinal Study. Canadian journal of diabetes. 2016;40(6):5705.

16. Rahmanian K, Shojaei M, Sotoodeh Jahromi A, Madani A. The Association Between Pre-Diabetes With Body Mass Index and Marital Status in an Iranian Urban Population. Glob J Health Sci. 2015;8(4):95-101.

17. Yazdanpanah L, Shahbazian HB, Moravej Aleali A, Jahanshahi A, Ghanbari S, Latifi SM. Prevalence, awareness and risk factors of diabetes in Ahvaz (South West of Iran). Diabetes \& metabolic syndrome. 2016;10(2 Suppl 1):S114-8.

18. Mirzaei M, Rahmaninan M, Mirzaei M, Nadjarzadeh A, Dehghani Tafti AA. Epidemiology of diabetes mellitus, pre-diabetes, undiagnosed and uncontrolled diabetes in Central Iran: results from Yazd health study. BMC public health. 2020;20(1):166-.

19. Esteghamati A, Meysamie A, Khalilzadeh O, Rashidi A, Haghazali M, Asgari F, et al. Third national Surveillance of Risk Factors of Non-Communicable Diseases (SuRFNCD-2007) in Iran: methods and results on prevalence of diabetes, hypertension, obesity, central obesity, and dyslipidemia. BMC public health. 2009;9:167-.

20. Safari-Faramani R, Rajati F, Tavakol K, Hamzeh B, Pasdar Y, Moradinazar M, et al. Prevalence, Awareness, Treatment, Control, and the Associated Factors of Diabetes in an Iranian Kurdish Population. Journal of diabetes research. 2019;2019:5869206. 
21. Najafipour H, Sanjari M, Shokoohi M, Haghdoost A-A, Afshari M, Shadkam M, et al. Epidemiology of diabetes mellitus, pre-diabetes, undiagnosed and uncontrolled diabetes and its predictors in general population aged 15 to 75 years: A community-based study (KERCADRS) in southeastern Iran. Journal of Diabetes. 2015;7(5):613-21.

22. Akbarzadeh A, Salehi A, Molavi Vardanjani H, Poustchi H, Gandomkar A, Fattahi MR, et al. Epidemiology of Adult Diabetes Mellitus and its Correlates in Pars Cohort Study in Southern Iran. Archives of Iranian medicine. 2019;22(11):633-9.

23. Khorrami Z, Yarahmadi S, Etemad K, Khodakarim S, Kameli ME, Hazaveh ARM. Urban-Rural Differences in the Prevalence of Self-Reported Diabetes and its Risk Factors: The WHO STEPS Iranian Noncommunicable Disease Risk Factor Surveillance in 2011. Iranian journal of medical sciences. 2017;42(5):481-7.

24. Chentli F, Azzoug S, Mahgoun S. Diabetes mellitus in elderly. Indian J Endocrinol Metab. 2015;19(6):744-52.

25. Honarvar B, Banakar M, Hassani N, Movahednezhad Y, Gheibi Z, Bagheri Lankarani K. From Iceberg of Pre-diabetes to Poor Glycemic Control in Diabetics: An Elderly Based Study in Shiraz, South of Iran. Int J Prev Med. 2019;10:171-.

26. Emdin CA, Anderson SG, Woodward M, Rahimi K. Usual Blood Pressure and Risk of New-Onset Diabetes: Evidence From 4.1 Million Adults and a Meta-Analysis of Prospective Studies. J Am Coll Cardiol. 2015;66(14):1552-62.

27. Barzin M, Asghari G, Hosseinpanah F, Mirmiran P, Azizi F. The association of anthropometric indices in adolescence with the occurrence of the metabolic syndrome in early adulthood: Tehran Lipid and Glucose Study (TLGS). Pediatric obesity. 2013;8(3):170-7.

28. Namayandeh SM, Karimi A, Fallahzadeh H, Rahmanian M, Sadr Bafghi SM, Soltani M, et al. The incidence rate of diabetes mellitus (type II) and its related risk factors: A 10-year longitudinal study of Yazd Healthy Heart Cohort (YHHC), Iran. Diabetes \& Metabolic Syndrome: Clinical Research \& Reviews. 2019;13(2):1437-41.

29. Mirzaei M, Khajeh M, Askarishahi M, Azizi R. Behavioral and familial predictors of diabetes mellitus in adults aged 20-69 in Yazd, Iran during 2014-2015. Diabetes \& metabolic syndrome. 2018;12(5):667-71.

30. Najafipour M, Zareizadeh M, Najafipour F. Epidemiologic study of familial Type 2 Diabetes in Tehran. J Adv Pharm Technol Res. 2018;9(2):56-60.

31. Rashedi V, Asadi-Lari M, Delbari A, Fadayevatan R, Borhaninejad V, Foroughan M. Prevalence of diabetes type 2 in older adults: Findings from a large population-based survey in Tehran, Iran (Urban HEART-2). Diabetes \& metabolic syndrome. 2017;11 Suppl 1:S347-s50.

32. Derakhshan A, Sardarinia M, Khalili D, Momenan AA, Azizi F, Hadaegh F. Sex specific incidence rates of type 2 diabetes and its risk factors over 9 years of follow-up: Tehran Lipid and Glucose Study. PloS one. 2014;9(7):e102563. 
33. Khosravi A, Emamian MH, Hashemi H, Fotouhi A. Obesity is the Most Important Factor for Gender Inequality in Type 2 Diabetes Incidence in an Iranian Population. Int J Prev Med. 2019;10:215-.

34. Golozar A, Khademi H, Kamangar F, Poutschi H, Islami F, Abnet CC, et al. Diabetes mellitus and its correlates in an Iranian adult population. PloS one. 2011;6(10):e26725.

35. Peykari N, Djalalinia S, Qorbani M, Sobhani S, Farzadfar F, Larijani B. Socioeconomic inequalities and diabetes: A systematic review from Iran. J Diabetes Metab Disord. 2015;14:8-.

36. Yeh HC, Duncan BB, Schmidt MI, Wang NY, Brancati FL. Smoking, smoking cessation, and risk for type 2 diabetes mellitus: a cohort study. Annals of internal medicine. 2010;152(1):10-7.

37. Hou X, Qiu J, Chen P, Lu J, Ma X, Lu J, et al. Cigarette Smoking Is Associated with a Lower Prevalence of Newly Diagnosed Diabetes Screened by OGTT than Non-Smoking in Chinese Men with Normal Weight. PloS one. 2016;11(3):e0149234-e. 